\title{
Dynamical failure index of single layer Keiwitt latticed shell structures
}

\author{
Liming Zhu, Yun Sun*, Wenfeng Du and Zengguang Zhang \\ Institute of Steel and Spatial Structures in School of Civil Engineering and Architecture, Henan University, Kaifeng \\ 475004 China \\ ${ }^{*}$ Corresponding author: dwf@henu.edu.cn
}

\begin{abstract}
Based on the double control criterion of displacement and energy, a new index, dynamical damage index, for describing the dynamical damage extent in the single layer latticed shell structure is set up. The calculate method and change law of all kinds of consuming energy under the seismic action in the latticed shell structures are studied. Then the expression of dynamical damage index erected by combining the plastic consuming energy and maximum displacement is present. Moreover, the compare among the three index, dynamical damage index, displacement and plastic bar quantity, is completed by large numbers of parameter analysis in the single latticed shell structures. The results show that the discrepancy of analytical conclusion is distinct among the three index, dynamical damage index, displacement and plastic bar quantity to the latticed shell with local weakening stiffness, and the results of dynamical damage index are more reasonable. The dynamical failure index is in effect for the quantificational analysis of dynamical failure for single layer latticed shells.
\end{abstract}

\section{Introduction}

With the increase of external dynamic load, dynamic response of single layer latticed shell structure would develop. Structure will go through whole progress which the intact structure suffers from a dynamical failure and then collapses with a gradual increase of damage grade. At present, many of researches of single layer latticed shell structure describe the progress of structural dynamical failure and structural statue base on displacement index and plastic bar quantity index. However, according to practical analysis of latticed shell structure, displacement reflects the deformation of the structure but it is not able to distinguish structural damage accumulation process under cyclic load effect and plastic bar quantity reflects the grade of structural plasticity but it can't distinguish the deformation of latticed shell during damaging progress [1-3].

Initially, form the view of energy, this paper will analyse energy dissipation mechanism of single layer shell latticed. Subsequently, the paper will accord the dual-control guidelines of deformation and plastic cumulative energy dissipation to establish and apply dynamical failure index to analyse the extent of dynamical failure of single layer latticed shell structure. Ultimately, it will provide five cut-off values of dynamical failure index according to the degree of single layer latticed shell structure [4-7].

\section{Mechanism of the structural energy dissipation}

According to structural dynamics, differential equation system of motion that is considered the damping action of multidegree-of-freedom system which is under seismic action [8-10]:

$$
[M]\{\ddot{U}\}+[C]\{\dot{U}\}+[K]\{U\}=-[M]\left\{\ddot{U}_{g}\right\}
$$

In the equation: $[M],[K]$ and $[C]$ are mass matrix, stiffness matrix and damp matrix; $\{U\}$ is the displacement of column vector with respect to ground; $\{\dot{U}\}$ is the relative velocity of column vector; $\{\ddot{U}\}$ is the relative acceleration the column vector; $\left\{\ddot{U}_{g}\right\}$ is the ground motion acceleration of column vector.

In equation (1), $[K]$ and $\{U\}$ are restoring vectors which can be denoted by $\{F\}$, so equation (1) can be transformed as:

$$
[M]\{\ddot{U}\}+[C]\{\dot{U}\}+\{F\}=-[M]\left\{\ddot{U}_{g}\right\}
$$

Multiply both sides of equation (2) by $\{\dot{U}\}$, and then do integral from zero time to t0 time, as a result: 
The Fc is damping force.

$$
\begin{aligned}
& {[M] \int_{0}^{t_{0}}\{\ddot{U}\}\{\dot{U}\} d t+[C] \int_{0}^{t_{0}}\{\dot{U}\}\{\dot{U}\} d t+\int_{0}^{t_{0}}\{F\}\{\dot{U}\} d t} \\
& =-\left[[M] \int_{0}^{t_{0}}\{\ddot{U} g\}\{\dot{U}\} d t\right] \\
& {[M] \int_{0}^{t_{0}}\{\ddot{U}\}\{\dot{U}\} d t=\int_{0}^{t_{0}}[M]\{\ddot{U}\} d\{U\}=\frac{1}{2} \int_{0}^{t_{0}}[M] d\{\dot{U}\}^{2}} \\
& =\int_{0}^{t_{0}} d \frac{[M]\{\dot{U}\}^{2}}{2}=\int_{0}^{t_{0}} d E_{d} \\
& {[C] \int_{0}^{t_{0}}\{\dot{U}\}\{\dot{U}\} d t=\int_{0}^{t_{0}}[C]\{\dot{U}\} d\{U\}} \\
& =\int_{0}^{t_{0}}\left\{F_{c}\right\} d\{U\}=\int_{0}^{t_{0}} d E_{c}
\end{aligned}
$$

$$
\begin{aligned}
& \int_{0}^{t_{0}}\{F\}\{\dot{U}\} d t=\int_{0}^{t_{0}}\{F\} d\{U\}=\int_{0}^{t_{0}} d E_{y} \\
& \left.-[M] \int_{0}^{t_{0}}\left\{\ddot{U}_{g}\right\}\{\dot{U}\} d t\right]=-\int_{0}^{t_{0}}[M]\left\{\ddot{U}_{g}\right\} d\{U\} \\
& =-\int_{0}^{t_{0}}\left\{F_{g}\right\} d\{U\}=-\int_{0}^{t_{0}} d E_{t}
\end{aligned}
$$

The $\mathrm{F}_{\mathrm{ig}}$ is the impetus correspondent with the applied acceleration wave.

Therefore, the structure of the Eqs.(3) in turn indicates the structural kinetic energy $\left(E_{d}\right)$, damping energy dissipation $\left(E_{c}\right)$, total deformation energy $\left(E_{y}\right)$ and total energy of structure absorption $\left(E_{t}\right)$ from the zero moment to the $t_{0}$ moment.

When elastic-plastic analysis is conducted on the structure, the restoring force of elastic-plastic can be composed by elastic restring force and plastic yield force.

$$
\begin{aligned}
& \{F\}=[K]\{U\}+\{B\} \\
& \int_{0}^{t_{0}}\{F\}\{\dot{U}\} d t=\int_{0}^{t_{0}}\{F\} d\{U\} \\
& =\int_{0}^{t_{0}}[K]\{U\} d\{U\}+\int_{0}^{t_{0}}\{B\} d\{U\} \\
& =\int_{0}^{t_{0}} d E_{e}+\int_{0}^{t_{0}} d E_{p}
\end{aligned}
$$

The total deformation energy of this structure is $E_{y}$, can be expressed as the summation of elastic strain energy is $E_{\varepsilon}$, and plastic cumulative hysteretic energy is $E_{p}$. It is shown:

$$
E_{y}=E_{e}+E_{p}
$$

Based on the principle of conservation of energy, the Eqs.(3) sets up during every moment of the whole process.

Therefore, plug Eqs.(10) into Eqs.(3), the equation of the total energy can be showed:

$$
E_{d}+E_{c}+E_{e}+E_{p}=E_{t}
$$

The above energy dissipation takes different proportions in different stages in the whole geological process.

The Fig.1. is relation curve of the total energy and each energy dissipation that the single-layer reticulated shell as the peak value $0.8 \mathrm{~g}$ under the action of EL2-Centro(1940) $3 \mathrm{~d}$ acceleration seismic wave after the above example in this paper. 


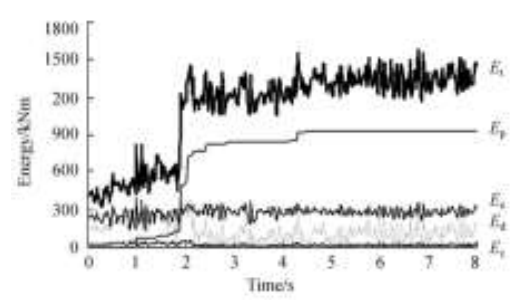

Fig. 1. Relationship of total energy and subentry

The Fig.1. illustrates that before one second, that seismic energy is shared by elastic deformation energy and damping energy dissipation structure kinetic energy, respectively $57.2 \%, 5.2 \%, 37.6 \%$. After one second, the member bar goes into plasticity and produces plastic energy dissipation. With the time going by, the energy of plastic dissipation becomes more and then it takes the main part of energy dissipation, almost amounting to $64.1 \%$.

\section{Double-control of the criterion and dynamical failure index}

From the mechanism of energy dissipation structure, for a moderate yield of net shell structure, the main energy consumption form is the plastic energy dissipation, $E_{p}$. Therefore, there is some evidence about damage index of the accumulated plastic energy dissipation structural. However, the energy usually reflects the destruction of the structure of overall situation not the whole details. For example, each energy value can be correspond more than one damage form, while it can't make out the specific form.

The other most important criteria in structural failure is the deformation, which shows structural maximum displacement response, but does not distinguish the structure under repeated load damage accumulation process. Therefore, from the two aspects, energy and deformation, the dynamic failure of the structure is expressed as a linear combination of the maximum deformation and the plastic cumulative consumption and can be expressed by dynamic damage index $D$. And the double control criteria of dynamic strength failure can be established, showing that the energy of maximum deformation and cumulative plastic deformation has an effect the influence of the structure damage. Try to ensure that lines are no thinner than 0.25 point.

$$
D=\frac{\delta_{M}}{\delta_{U}}+\frac{\beta}{Q_{y} \delta_{U}} \int d E_{p}
$$

The $D$ as dynamic damage index is structural damage index; $\delta_{M}$ as structural maximum displacement response; $\delta_{U}$ as the limit displacement response under the static load; $Q_{y}$ as the yield strength of material; $\beta$ as the coefficient of structure system, usually 1.0 for the common structure; $\int d E_{p}$ as the cumulative plastic energy dissipation.

The first paragraph on the right of Eqs.(12) is the proportion of structural displacement response and ultimate displacement response, showing the development of displacement ductility of structure. The second paragraph is the proportion of structure of the plastic energy dissipation and limit of energy dissipation, showing the development of structure of plastic energy dissipation.

\section{The comparison between dynamical failure index and the displacement index, the plastic bar quantity index}

The $\mathrm{K}_{8,6}$ type single layer lattice shell structure with span $40 \mathrm{~m}$ as an example in this paper. Analyze the structure damage index becomes of law in the structural dynamic failure of the whole process, and compare it with displacement and plastic bar quantity.

\subsection{Structure Model}

The structural model as shows in Fig.2., it is a single layer latticed shell structure K8, 6. The structure span is $40 \mathrm{~m}$, calculated five cases of the rise span ratios respectively 1/7,1/6,1/5,1/4 and 1/3. The total number of structural bar quantities is 456, the total number of nodes is 169. The structure is clamped, the material is Q235 steel, the Young's modulus (E) is $206 \mathrm{kN} / \mathrm{mm} 2$, the Poisson's ratio is 0.3 . Using the isotropic intensified Mises elastic-perfectly plastic material, the yield strength is $215 \mathrm{~N} / \mathrm{mm} 2$, the Rayleigh damping and the ratio is 0.02 . Select four kinds of round tube section $60 \times 3.5 \mathrm{~mm}, 75.5 \times 3.75 \mathrm{~mm}, 89 \times 4 \mathrm{~mm}, 114 \times 4 \mathrm{~mm}$ respectively. 


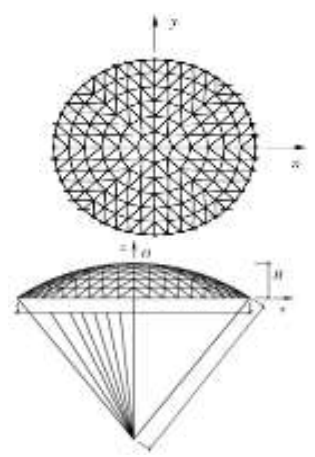

Fig. 2. Geometrical model of the latticed shell

Using the universal finite element software of ANSYS to analysis dynamic time-histories analysis, seismic load selected EL2-Centro (1940) three-dimensional acceleration speed of earthquake wave. Using Pipe 20 beam elements, each section has eight output points, as shown in Fig.3. When there is an output point into the plastic state, recorded as $1 \mathrm{P}$, there are two output points enter the plastic, recorded as $2 \mathrm{P}$, and so on.

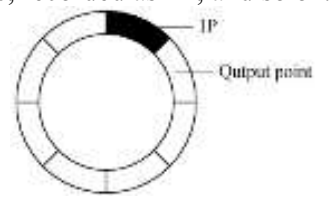

Fig. 3. Section of Pipe20 element

\subsection{Calculative results}

When span ratio structures takes $1 / 5$, analyse the structure of elastic-plastic dynamic and time-historical, recording structural time displacement curve of the maximum displacement nodes under different peak of earthquake wave, as shown in Fig.4.

The Fig.4. shows that when the earthquake wave peak is less than $0.6 \mathrm{~g}$, structure remained stable vibration. When earthquake wave peaking at $0.7 \mathrm{~g}$, the maximum displacement node increases significantly, and there is a jump, after the jump, time displacement curve is in the new position to vibrate stably. Earthquake wave peak reaches $0.8 \mathrm{~g}$, there has a greater structural displacement jump, at the new location can remain steady vibration. Earthquake wave peak reaches $0.9 \mathrm{~g}$, the structure collapsed.

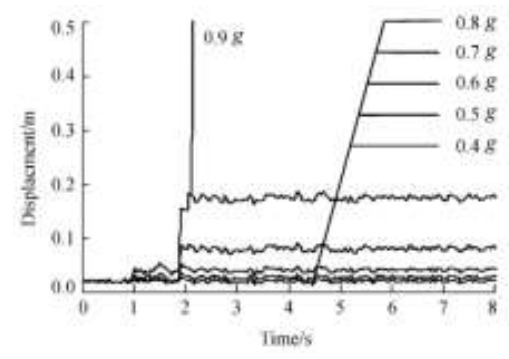

Fig. 4. Curve of time-history of maximum displacement node

The Fig. 5 is a deformation of the structure and the bar distribution of plastic. The Table 1. shows the structural maximum displacement response, dynamic failure index, the number of plastic rod and a description of the extent of structural damage of calculated. 


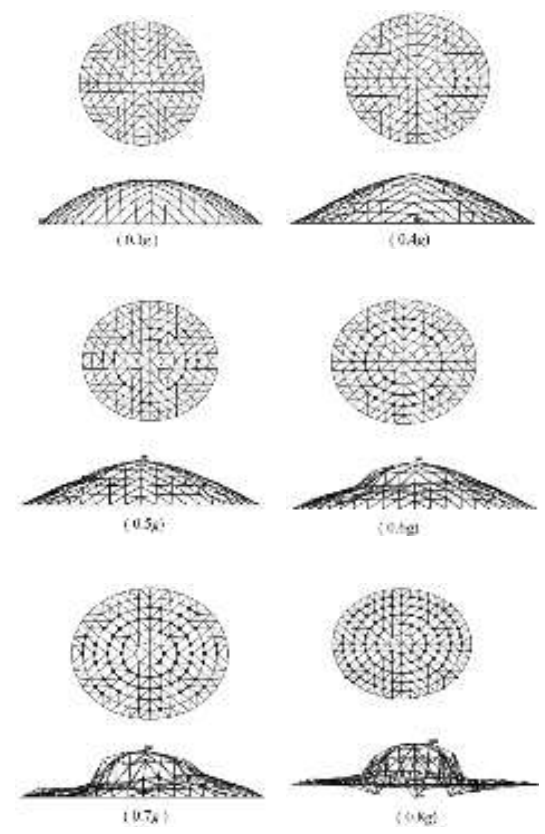

Fig. 5. Structural deformation and distribution of plastic bars (plastic bars are thick)

Table 1. Calculated results of indexes with different peak value of seismic wave

\begin{tabular}{ccccccccc}
\hline $\begin{array}{c}\text { Peak value of earthquake } \\
\text { wave }\end{array}$ & $0.2 \mathrm{~g}$ & $0.3 \mathrm{~g}$ & $0.4 \mathrm{~g}$ & $0.5 \mathrm{~g}$ & $0.6 \mathrm{~g}$ & $0.7 \mathrm{~g}$ & $0.8 \mathrm{~g}$ & $0.9 \mathrm{~g}$ \\
\hline Max displacement/mm & 25.43 & 26.30 & 27.27 & 33.04 & 49.56 & 103.55 & 392.06 & $\infty$ \\
\hline Dynamical failure index & 0.098 & 0.101 & 0.115 & 0.14 & 0.282 & 0.724 & 1.945 & $\infty$ \\
\hline Number of bars of 1P & 0 & 0 & 4 & 17 & 31 & 60 & 211 & 456 \\
\hline Number of bars of 8P & 0 & 0 & 2 & 14 & 24 & 48 & 164 & 456 \\
\hline Grade of damage & intact & intact & intact & intact & $\begin{array}{c}\text { slight } \\
\text { damage }\end{array}$ & $\begin{array}{c}\text { moderate } \\
\text { damage }\end{array}$ & $\begin{array}{c}\text { severe } \\
\text { damage }\end{array}$ & collapse \\
\hline
\end{tabular}

From Fig.5 and Table 1, when the earthquake wave peak value reach $0.2 \mathrm{~g}$ and $0.3 \mathrm{~g}$, there are no bars into the plastic, structure is perfectly elastic, the dynamic failure index in this range is below 0.1 . When the earthquake wave peak value is $0.4 \mathrm{~g}$, the third ring portion of the bar member first to enter plastic, structure began in working condition with elasticplastic, the maximum displacement nodes in the third ring and the diameter of the rib, the dynamical failure index is 0.115 . When the earthquake wave peak at $0.5 \mathrm{~g}$ and $0.6 \mathrm{~g}$, fourth and second rings began to enter the plastic, dynamical failure index are 0.14 and 0.282 . The earthquake wave peak reaches $0.7 \mathrm{~g}$, into the plastic bars increased significantly, dynamical failure index increase to 0.724 . When earthquake wave peak reaches $0.8 \mathrm{~g}$, into the plastic bars have been distributed to the ring bars, radial bars and diagonal bars, dynamical failure index is 1.945 .

To further reflect the contact between dynamical failure index and development level of plastic structure, the maximum displacement of the structure, the number of bars into the plastic. Calculate the dynamical response of different rise span ratio and different earthquake waves peak value, results are shown in Table 2.

Table 2. Summary of calculated results of different indexes

\begin{tabular}{|c|c|c|c|c|c|c|}
\hline $\begin{array}{l}\text { Ratio of } \mathrm{H} \\
\text { to } \mathrm{L}\end{array}$ & $\begin{array}{c}\text { Peak value } \\
\text { of } \\
\text { earthquake } \\
\text { wave }\end{array}$ & $\begin{array}{c}\text { Dynamical } \\
\text { failure index }\end{array}$ & $\begin{array}{l}\text { Displacement } \\
/ \mathrm{mm}\end{array}$ & $\begin{array}{l}\text { Number of } \\
\text { bars of } 1 P\end{array}$ & $\begin{array}{l}\text { Number of } \\
\text { bars of } 8 \mathrm{P}\end{array}$ & $\begin{array}{l}\text { Grade of } \\
\text { damage }\end{array}$ \\
\hline \multirow{2}{*}{$1 / 7$} & $0.1 \mathrm{~g}$ & 0.275 & 46.47 & 30 & 22 & intact \\
\hline & $0.2 \mathrm{~g}$ & $\infty$ & $\infty$ & 456 & 456 & collapse \\
\hline \multirow{5}{*}{$1 / 6$} & $0.1 \mathrm{~g}$ & 0.095 & 23.23 & 0 & 0 & intact \\
\hline & $0.2 \mathrm{~g}$ & 0.121 & 32.43 & 15 & 11 & slight damage \\
\hline & $0.3 \mathrm{~g}$ & 0.327 & 66.95 & 49 & 38 & slight damage \\
\hline & $0.4 \mathrm{~g}$ & 1.679 & 237.971 & 102 & 84 & $\begin{array}{c}\text { moderate } \\
\text { damage }\end{array}$ \\
\hline & $0.5 \mathrm{~g}$ & $\infty$ & $\infty$ & 456 & 456 & collapse \\
\hline \multirow{3}{*}{$1 / 5$} & $0.2 \mathrm{~g}$ & 0.098 & 25.43 & 0 & 0 & intact \\
\hline & $0.3 \mathrm{~g}$ & 0.101 & 26.30 & 0 & 0 & intact \\
\hline & $0.4 \mathrm{~g}$ & 0.115 & 27.27 & 4 & 2 & slight damage \\
\hline
\end{tabular}




\begin{tabular}{|c|c|c|c|c|c|c|}
\hline & $0.5 \mathrm{~g}$ & 0.14 & 33.04 & 17 & 14 & slight damage \\
\hline & $0.6 \mathrm{~g}$ & 0.282 & 49.56 & 31 & 24 & slight damage \\
\hline & $0.7 \mathrm{~g}$ & 0.724 & 103.55 & 60 & 48 & slight damage \\
\hline & $0.8 \mathrm{~g}$ & 1.945 & 392.06 & 211 & 164 & moderate \\
\hline & $0.9 \mathrm{~g}$ & $\infty$ & $\infty$ & 456 & 456 & collapse \\
\hline & $0.2 \mathrm{~g}$ & 0.086 & 18.88 & 0 & 0 & intact \\
\hline & $0.3 \mathrm{~g}$ & 0.090 & 19.79 & 0 & 0 & intact \\
\hline & $0.4 \mathrm{~g}$ & 0.094 & 20.70 & 0 & 0 & intact \\
\hline $1 / 4$ & $0.5 \mathrm{~g}$ & 0.098 & 21.61 & 0 & 0 & intact \\
\hline $1 / 4$ & $0.6 \mathrm{~g}$ & 0.102 & 22.51 & 0 & 0 & intact \\
\hline & $0.7 \mathrm{~g}$ & 0.112 & 23.45 & 4 & 2 & slight damage \\
\hline & $0.8 \mathrm{~g}$ & 0.141 & 34.58 & 18 & 12 & slight damage \\
\hline & $0.9 \mathrm{~g}$ & 0.203 & 36.08 & 29 & 24 & slight damage \\
\hline & $0.2 \mathrm{~g}$ & 0.066 & 14.47 & 0 & 0 & intact \\
\hline & $0.3 \mathrm{~g}$ & 0.070 & 15.36 & 0 & 0 & intact \\
\hline & $0.4 \mathrm{~g}$ & 0.074 & 16.26 & 0 & 0 & intact \\
\hline & $0.5 \mathrm{~g}$ & 0.078 & 17.15 & 0 & 0 & intact \\
\hline $1 / 3$ & $0.6 \mathrm{~g}$ & 0.082 & 18.05 & 0 & 0 & intact \\
\hline & $0.7 \mathrm{~g}$ & 0.086 & 18.94 & 0 & 0 & intact \\
\hline & $0.8 \mathrm{~g}$ & 0.090 & 19.84 & 0 & 0 & intact \\
\hline & $0.9 \mathrm{~g}$ & 0.100 & 20.76 & 0 & 0 & intact \\
\hline
\end{tabular}

Calculated from the data in Table 2. shows, many states experienced plastic evolving between shell structures to collapse entirely from the state in good condition. With the development of plastic, deepen structural damage, dynamical failure index increases, structure maximum displacement nodes increases, increasing the number of the bar members into plastic. When the dynamical failure index is less than 0.1 , there is no structure in the bar into the plastic, structure is in elastic working condition, structurally in pretty good shape, this time corresponding to the maximum displacement response is about $1 / 1500$ of structure spans. the basic dynamic failure index is within the range of 0.1 to 0.8 , the structure has a small bar into the plastic, the plastic is not in-depth development, can consider there is a slight structural damage, then the corresponding to maximum displacement response is approximately $1 / 1500$ to $1 / 400$ of structure spans, the percentage of plastic bars is about $0 \%$ to $13 \%$.

Dynamical failure index is basically in the range between 0.8 and 2.0, structure has a certain number of bars into the plastic, plastic level of development is moderate, that generates moderate structural damage, then the corresponding to maximum displacement response is approximately $1 / 400$ to $1 / 100$ of structure spans, the percentage of plastic bars is $13 \%$ to $45 \%$. Dynamical failure index exceeds 2.0, many bars of structure into the plastic state, plastic deformation development is also more serious, corresponding structure displacement are large, the structure can be considered at this time it has reached the ultimate of bearing capacity, generating dynamical strength failure.

Therefore, $D$ is equal to 2 as the cut-off value of damage to the structure, the corresponding maximum displacement response and the percentage of $1 \mathrm{P}$ bars is about $1 / 100$ and $45 \%$, respectively. This is the same basically as the literature [1] proposed that use $1 / 100$ of structure span (1P percentage is $42 \%$ ) as limit of dynamic failure.

In order to contrast the result of dynamical failure index, maximum displacement and the analysis result of the proportion of the bars into the plastic. Fig.6. show the relational comparison chart respectively.

From Fig.6 dynamical failure index basically presents positive relationship with structural maximum displacement and the proportion of 1P bar; structural maximum displacement becomes larger with the increase of dynamical failure index. Analyzed the structure of the damage from failure index, structural maximum displacement, and the plastic bar, it also can get the same result.

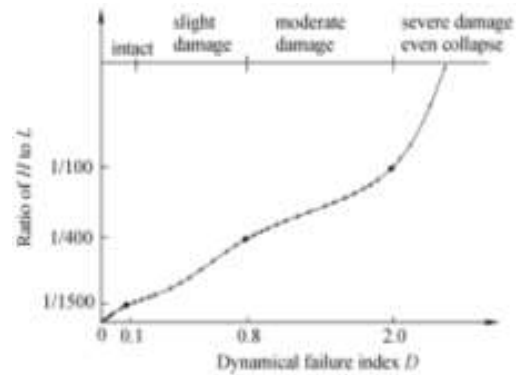

(a) 


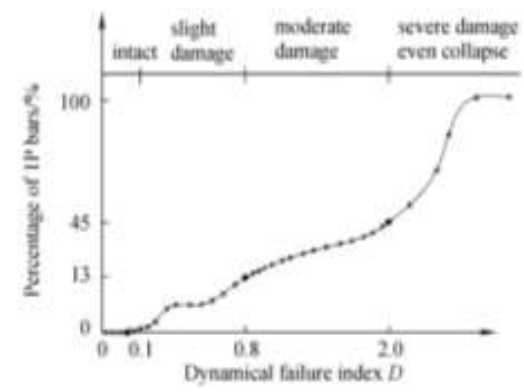

(b)

Fig. 6. (a) Relationship of dynamical damage index and maximum displacement; (b) Relationship of dynamical damage index and proportion of $1 \mathrm{P}$ plastic bars

While, the proportion of structural maximum displacement and plastic bar is from the development of displacement ductility and structure of plastic energy dissipation, while dynamical failure index is from the former two considerations. According to the method to calculate, when seismic wave peak is $0.5 \mathrm{~g}$, the structural maximum displacement is $375.12 \mathrm{~mm}$, nearly $1 / 100$ of the whole span. From the point of structural maximum displacement, this structure has seriously been damaged. While, only changed the structure into the plastic bar section of this 4 root, from the point of proportion of plastic bar, the structure can be thought that it has been lightly damaged. Just as demonstrates in Fig. 7. the structure in the maximum displacement has been damaged in some parts and it influences the formal use. If the four bars in damaged part are replaced, the whole structure will be fine. Therefore, it is not suitable to say that the structure has been seriously damaged or slightly damaged. The dynamical failure index is 0.82 from the point of dynamical failure index, in the secondary damage range

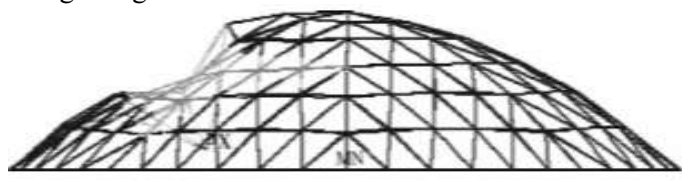

Fig. 7. Structural deformation after some bars are changed

\section{Different damage levels of the corresponding to boundary index}

According to the division of the habit of building structures, where the dynamical failure of single layer latticed shell structure is divided into five levels, they are largely intact, slight damage, moderate damage, serious damage, the collapse. According to the foregoing calculation results of the analysis, can correspond to given single layer Kiewit latticed shell structure of different control index extent of dynamical failure, as shown in Table 3 .

Table 3. Division of dynamical damage grade and the corresponding indexes

\begin{tabular}{|c|c|c|c|c|c|}
\hline Grade of damage & Intact & Slight damage & Moderate damage & Severe damage & Collapse \\
\hline Dynamical failure index & $0 \leqslant \mathrm{D}<0.2$ & $0.2 \leqslant \mathrm{D}<0.8$ & $0.8 \leqslant \mathrm{D}<2.0$ & $2.0 \leqslant \mathrm{D}$ & $\infty$ \\
\hline $\begin{array}{l}\text { Ratio of max displacement } \\
\text { to span }\end{array}$ & $0 \leqslant \mathrm{U}<1 / 1500$ & $1 / 1500 \leqslant U<1 / 1400$ & $1 / 400 \leqslant U<1 / 100$ & $1 / 100 \leqslant U$ & $\infty$ \\
\hline Percentage of plastic bars & $\mathrm{P}=0 \%$ & $0 \% \leqslant \mathrm{P}<13 \%$ & $13 \% \leqslant \mathrm{P}<45 \%$ & $45 \% \leqslant \mathrm{P}<100 \%$ & $\mathrm{P}=100 \%$ \\
\hline Description of phenomena & $\begin{array}{l}\text { all elements are } \\
\text { in elastic }\end{array}$ & $\begin{array}{c}\text { few elements are } \\
\text { plastic, displacement } \\
\text { is minor, equipment } \\
\text { are not damaged, } \\
\text { cost for repair is } \\
\text { few. }\end{array}$ & $\begin{array}{l}\text { a few elements are } \\
\text { plastic, } \\
\text { displacement is } \\
\text { big, some } \\
\text { equipment are } \\
\text { damaged, cost for } \\
\text { repair is notable. }\end{array}$ & $\begin{array}{l}\text { many elements } \\
\text { are plastic, } \\
\text { displacement is } \\
\text { prodigious, } \\
\text { equipment are } \\
\text { devastated, cost } \\
\text { for repair are } \\
\text { more than that for } \\
\text { build. }\end{array}$ & $\begin{array}{l}\text { the structure } \\
\text { is collapsed }\end{array}$ \\
\hline
\end{tabular}

\section{Conclusion}

1) Through the analysis of span of $40 \mathrm{~m}$ of $\mathrm{K} 8,6$ single layer spherical latticed shell structure, it is appropriate to use dynamic failure index $\mathrm{D}=2.0$ as the dividing line when the structure is serious damaged, then the corresponding maximum displacement response and the $1 \mathrm{P}$ bar percentage are about $1 / 100$ and $45 \%$, respectively.

2) The dynamic failure index is also reflecting the impact of structural deformation and plastic cumulative energy to structural damage, it is favourable to comprehensive analyse the structure dynamical failure situation. For shell structure of uniform initial configuration, the result of analysis of dynamic failure index shows good consistency with responds of maximum displacement, the results of analysis of the percentage of plastic bars. But for the shell structure of a weak 
local stiffness, there is a greater difference between the three, the analysis results of dynamical failure index are more moderate.

3) Structural damage state under dynamic loads cannot simply attributed two states, damage or no destruction. This article according to the division habit of building structures, gives largely intact, slight damage, moderate damage, serious damage, the collapse, five levels corresponding to dynamical failure index cut-off value, it is convenient to determine the dynamical damage extent of latticed shell structure.

\section{References}

1. S.Z. Shen, X.D. Zhi. Failure mechanism of reticular shells subjected to dynamic actions, China Civil Engineering Journal 38,11(2005).

2. J.H. Ye, Z.Y. Shen. Experimental research on dynamical stability of single layer latticed shell structures, Space Structure 3, 34(1997).

3. O.S. Kat, M.M. Shou, M. Mukaiyama. Study on Dynamic Behavior and Collapse Acceleration of single Layer Reticular Domes Subjected to Horizontal and Vertical Earthquake Motions, Structural and Construction Engineering 47,89(1995)

4. F. Feng, S.Z. Shen. Study on the shaking table experiment and the vibration reducing experiment of single Layer reticulated shells, Journal of H ARBIN University of Engineering and architecture 33,18(2000).

5. Z.X. Li, Z.Y. Shen, C.G. Deng. Judging criterion on nonlinear dynamical stability for truss structures, Journal of Tong Ji University 28,148(2000).

6. W.F. Du, B.Q. Gao, S.L. Dong. New Judgment Method On Dynamic Instability of Truss Structures: Stress Rate Method, Journal of Zhejiang University: Engineer science 40,506(2006).

7. Y.J. Park, A.H. Sang, Y.K. Wen. Mechanistic seismic damage model for reinforced concrete, Journal of structural engineering, 111,722(1985).

8. X.Y. Yu, F. Fan, S.Z. Shen. Study on the aseismic performance of single layer reticulated domes J. Xi'an Univ. of Arch. \& Tech (Natural Science Edition) 38,442(2006).

9. J.F. Zhang, J.P. Hao. Research on the ultimate strength capacity of an arch steel frame using ANSYS J. Xi'an Univ. of Arch. \& Tech (Natural Science Edition) 40,71(2008).

10. YB9254295, Division standard grade of earthquake damaged industry buildings. 